\title{
Osteo-/odontogenic differentiation of BMP2 and VEGF gene-co-transfected human stem cells from apical papilla
}

\author{
WEN ZHANG，XIAOLEI ZHANG，JUNQI LING，XI WEI and YUTAO JIAN \\ Guangdong Key Laboratory of Stomatology, Department of Operative Dentistry and Endodontics, \\ Guanghua School and Hospital of Stomatology, Sun Yat-sen University, Guangzhou, Guangdong 510055, P.R. China
}

Received April 4, 2015; Accepted February 4, 2016

DOI: $10.3892 / \mathrm{mmr} .2016 .4993$

\begin{abstract}
Stem cells from apical papilla (SCAP) possess clear osteo-/odontogenic differentiation capabilities, and are regarded as the major cellular source for root dentin development. Bone morphogenetic protein 2 (BMP2) and vascular endothelial growth factor (VEGF) serve pivotal roles in the modulation of tooth development and dentin formation. However, the synergistic effects of BMP2 and VEGF on osteo-/odontogenic differentiation of SCAP remain unclear. The current study aimed to investigate the proliferative and osteo-/odontogenic differentiating capabilities of BMP2 and VEGF gene-co-transfected SCAP (SCAP-BMP2-VEGF) in vitro. The basic characteristics of the isolated SCAP were identified by the induction of multipotent differentiation and by flow cytometry. Lentiviral vector-mediated gene transfection was conducted with SCAP in order to construct blank vector-transfected SCAP (SCAP-green fluorescent protein), BMP2 gene-transfected SCAP (SCAP-BMP2), VEGF gene-transfected SCAP (SCAP-VEGF) and SCAP-BMP2-VEGF. The Cell Counting Kit 8 assay was used to analyze the proliferative capacities of the four groups of cells. The expression of osteo-/odontogenic genes and proteins in the cells were evaluated by reverse transcription-quantitative polymerase chain reaction and western blotting. The mineralized nodules formed by the four group cells were visualized by alkaline phosphatase (ALP) staining. Among the four groups of cells, SCAP-VEGF was demonstrated to exhibit increased proliferation, and SCAP-BMP2-VEGF exhibited reduced proliferation during eight days observation. SCAP-BMP2-VEGF exhibited significantly increased expression levels of ALP, osteocalcin, dentin sialophosphoprotein,
\end{abstract}

Correspondence to: Professor Junqi Ling, Guangdong Key Laboratory of Stomatology, Department of Operative Dentistry and Endodontics, Guanghua School of Stomatology, Sun Yat-sen University, 56 Ling Yuan Xi Road, Guangzhou, Guangdong 510055, P.R. China E-mail: lingjq@mail.sysu.edu.cn

Key words: stem cells from apical papilla, bone morphogenetic protein 2, vascular endothelial growth factor, proliferation, gene transfection, osteo-/odontogenic differentiation dentin matrix acidic phosphoprotein gene 1 and dentin sialoprotein than the other three groups at the majority of the time points. Furthermore, the SCAP-BMP2-VEGF group exhibited a significantly greater number of ALP-positive mineralized nodules than the other groups following 16 days culture in vitro. In conclusion, lentiviral vector-mediated BMP2 and VEGF gene co-transfection significantly activated the osteo-/odontogenic differentiation of human SCAP.

\section{Introduction}

Stem cells from apical papilla (SCAP) are a type of multipotent mesenchymal stem cells, which can be isolated from the apical papilla of immature teeth $(1,2)$. SCAP possess the potential to differentiate into odontoblasts, which may contribute to dentin-pulp complex formation. SCAP also exhibit clear proliferative activity (3-5). Due to the clear osteo-/odontogenic potential and proliferative capacity, SCAP are regarded as valuable seed cells, and may be used in dentin regeneration.

SCAP have specific phenotypic markers, including STRO-1, CD146 and CD24 (3). STRO-1 and CD146 are specific markers of mesenchymal stem cells $(3,6)$. STRO-1- and CD146-positive SCAP have previously been revealed to exhibit osteo-/odontogenic potential (7). CD24, which had not been detected in dental pulp stem cells (DPSCs) (3), has been reported to be a specific marker of SCAP $(2,7)$.

Certain cytokines and growth factors participate in regulation of proliferation, differentiation and mineralization of SCAP, including bone morphogenetic protein (BMP) and vascular endothelial growth factor (VEGF) (8-12). A previous study has indicated that BMP2 gene transfection is an effective method to enhance the osteo-/odontogenic differentiation capacity of DPSCs by increasing osteo-/odontogenic gene and protein expression levels (12). Another previous study reported that lentiviral-mediated BMP2 gene transfection was effective in improving the odontogenic differentiation capacity of human SCAP in vitro (11). VEGF is also known to exhibit osteogenetic activity (13-15), and has been widely used in the regulation of proliferation and osteo-/odontogenic differentiation in stem cells derived from dental tissue (16-18).

The application of BMP2 or VEGF individually has been confirmed to be effective in improving osteo-/odontogenic differentiation of certain stem cells, however, simultaneous delivery of BMP2 and VEGF resulted in markedly improved 
results for osteogenesis (19-22). However, one study contradictorily reported that VEGF inhibited the expression of BMP2 and osteogenesis in rat bone marrow mesenchymal stem cells (BMMSCs) (23). The effects of BMP2 and VEGF gene co-transfection on the osteo-/odontogenic differentiation of SCAP require further elucidation. The aim of the current study was to analyze osteo-/odontogenic differentiation and the mineralization characteristics of human SCAP with lentiviral-mediated BMP2 and VEGF gene co-transfection.

\section{Materials and methods}

Isolation and identification of SCAP. Human SCAP were isolated from an extracted immature mandibular third molar of a male patient aged 18 years old by a method used in a previous study (11). All protocols were reviewed and approved by the Ethics Committee of Guanghua School and Hospital of Stomatology, Sun Yat-sen University (Guangzhou, China). The osteogenic and adipogenic differentiation capacities of SCAP were identified by Alizarin Red staining and Oil Red O staining (Cyagen Biosciences, Inc., Guangzhou, China), respectively (11). The typical phenotypes, including STRO-1/Alexa Fluor 647-Allophycocyanin (BioLegend, Inc., San Diego, CA, USA), CD146/Phycoerythrin (BD Pharmingen, San Diego, CA, USA), CD24/Fluorescein Isothiocyanate (FITC) (BD Pharmingen) and CD45/FITC (BD Pharmingen), using the 2nd passage of SCAP were assessed using a FACSCalibur flow cytometer (BD Biosciences, Franklin Lakes, NJ, USA).

Construction of lentivirus plasmid and cell infection. Human BMP2 and VEGF gene primers were designed and amplified as describedpreviously $(11,16)$. Theoligonucleotides were combined into the lentiviral vector pCDH-CMV-MCS-EF1-copGFP (pCDH; System Biosciences, Mountain View, CA, USA) to build the recombinant plasmids, $\mathrm{pCDH}-\mathrm{BMP} 2$ and $\mathrm{pCDH}-\mathrm{VEGF}$. The recombinant plasmids and packaging plasmids were then co-transfected into 293FT cells (Cyagen Biosciences, Inc.). The media of the 293FT cells containing lentivirus was collected 48 $\mathrm{h}$ after transfection, and then were purified by ultracentrifugation at $1,000 \mathrm{x} \mathrm{g}, 37^{\circ} \mathrm{C}$ for $10 \mathrm{~min}$, and the supernatant was subsequently filtered through a $0.2-\mu \mathrm{m}$ syringe filter (EMD Millipore, Billerica, MA, USA). The 4th passage SCAP were infected with the cell supernatants which contained lentiviral constructs (multiplicity of infection $=70$ ) to obtain SCAP-BMP2 and SCAP-VEGF. Furthermore, SCAP-BMP2-VEGF were generated by infecting SCAP with cell supernatants which contained lentiviral constructs expressing BMP2 and VEGF, sequentially. Serving as the control, a blank vector transfected with SCAP [SCAP-green fluorescent protein (GFP)] was constructed. The expression of BMP2 and VEGF in the four groups of cells was analyzed by reverse transcription-quantitative polymerase chain reaction (RT-qPCR) and western blot analysis four days subsequent to transfection.

Cell proliferation Cell Counting Kit 8 (CCK8) assay. Four groups of cells, SCAP-GFP, SCAP-BMP2, SCAP-VEGF and SCAP-BMP2-VEGF, were seeded into 96-well plates at a density of $2 \times 10^{3}$ cells/well and were cultured in $\alpha$-minimum essential medium (MEM) with $15 \%$ fetal bovine serum (FBS) (Cyagen Biosciences, Inc.). The proliferation rate of the cells
Table I. Reverse transcription-quantitative polymerase chain reaction primers.

\begin{tabular}{|c|c|c|}
\hline Gene & Primer sequence & $\begin{array}{l}\text { Product } \\
\text { size (bp) }\end{array}$ \\
\hline BMP2 & $\begin{array}{l}\text { F: 5'-CACTGTGCGCAGCTTCC-3' } \\
\text { R: 5'-CCTCCGTGGGGATAGAACTT-3' }\end{array}$ & 107 \\
\hline VEGF & $\begin{array}{l}\text { F: 5'-CTACCTCCACCATGCCAAGT-3' } \\
\text { R: 5'-AGCTGCGCTGATAGACATCC-3' }\end{array}$ & 104 \\
\hline ALP & $\begin{array}{l}\text { F: 5'-CTATCCTGGCTCCGTGCTC-3' } \\
\text { R: 5'-GCTGGCAGTGGTCAGATGTT-3' }\end{array}$ & 100 \\
\hline OCN & $\begin{array}{l}\text { F: 5'-CTCACACTCCTCGCCCTATT-3' } \\
\text { R: 5'-TTGGACACAAAGGCTGCAC-3' }\end{array}$ & 107 \\
\hline DSPP & $\begin{array}{l}\text { F: 5'-GCCACTTTCAGTCTTCAAAGAGA-3' } \\
\text { R: 5'-GCCCAAATGCAAAAATATGTAA-3' }\end{array}$ & 130 \\
\hline DMP1 & $\begin{array}{l}\text { F: 5'-AAAATTCTTTGTGAACTACGGAGG-3' } \\
\text { R: 5'-GAGCACAGGATAATCCCCAA-3' }\end{array}$ & 94 \\
\hline GAPDH & $\begin{array}{l}\text { F: 5'-AAGGTGAAGGTCGGAGTCAA-3' } \\
\text { R: 5'-AATGAAGGGGTCATTGATGG-3' }\end{array}$ & 108 \\
\hline \multicolumn{3}{|c|}{$\begin{array}{l}\text { bp, base pairs; F, forward; R, reverse; BMP2, bone morphogenetic } \\
\text { protein 2; VEGF, vascular endothelial growth factor; ALP, alkaline } \\
\text { phosphatase; OCN, osteocalcin; DSPP, dentin sialophosphoprotein; } \\
\text { DMP1, dentin matrix acidic phosphoprotein gene 1; GAPDH, glycer- } \\
\text { aldehyde 3-phosphate dehydrogenase. }\end{array}$} \\
\hline
\end{tabular}

was analyzed using the CCK8 assay kit (Dojindo Molecular Technologies, Inc., Kumamoto, Japan) on the 1st, 2nd, 4th and 8th days subsequent to gene transfection.

$R T-q P C R$. Total RNA was extracted from SCAP-GFP, SCAP-BMP2, SCAP-VEGF and SCAP-BMP2-VEGF using TRIzol (Invitrogen; Thermo Fisher Scientific, Inc., Waltham, MA, USA) on days 1, 4, 8 and 16 subsequent to transfection. The synthesis of complementary DNA (cDNA) was conducted using the RevertAid First Strand cDNA Synthesis kit (Thermo Fisher Scientific, Inc.), according to the manufacturer's protocol. For each sample $2 \mu \mathrm{g}$ RNA was used to synthesize the cDNA. The RT-qPCR reaction was conducted using iQ SYBR Green Supermix (BioRad Laboratories, Inc., Hercules, CA, USA) and regulated by the spectrofluorimetric iQ5 Thermal iCycler (BioRad Laboratories, Inc.). For PCR amplification, specific primers were used, as indicated in Table I. Initial denaturation was conducted at $95^{\circ} \mathrm{C}$ for $3 \mathrm{~min}$. This was succeeded by 30 cycles as follows: Denaturation, $95^{\circ} \mathrm{C}$ for $15 \mathrm{sec}$; annealing, $55^{\circ} \mathrm{C}$ for $30 \mathrm{sec}$; extension, $72^{\circ} \mathrm{C}$ for $1 \mathrm{~min}$. This was followed by a final extension at $72^{\circ} \mathrm{C}$ for $7 \mathrm{~min}$, prior to storage at $4^{\circ} \mathrm{C}$ for $10 \mathrm{~min}$. The mRNA expression of VEGF (GenBank accession no. MIM 612369), BMP2 (GenBank accession no. MIM 612369) and four osteo-/odontogenic genes, including alkaline phosphatase (ALP; GenBank accession no. MIM 612369), osteocalcin (OCN; GenBank accession no. MIM 612369), dentin sialophosphoprotein (DSPP; GenBank accession no. MIM 612369) and dentin matrix acidic phosphoprotein gene 1 (DMP1; GenBank accession no. MIM 612369), were analyzed by RT-qPCR. Glyceraldehyde 3-phosphate dehydrogenase (GAPDH) was selected as the reference gene (Table I). 

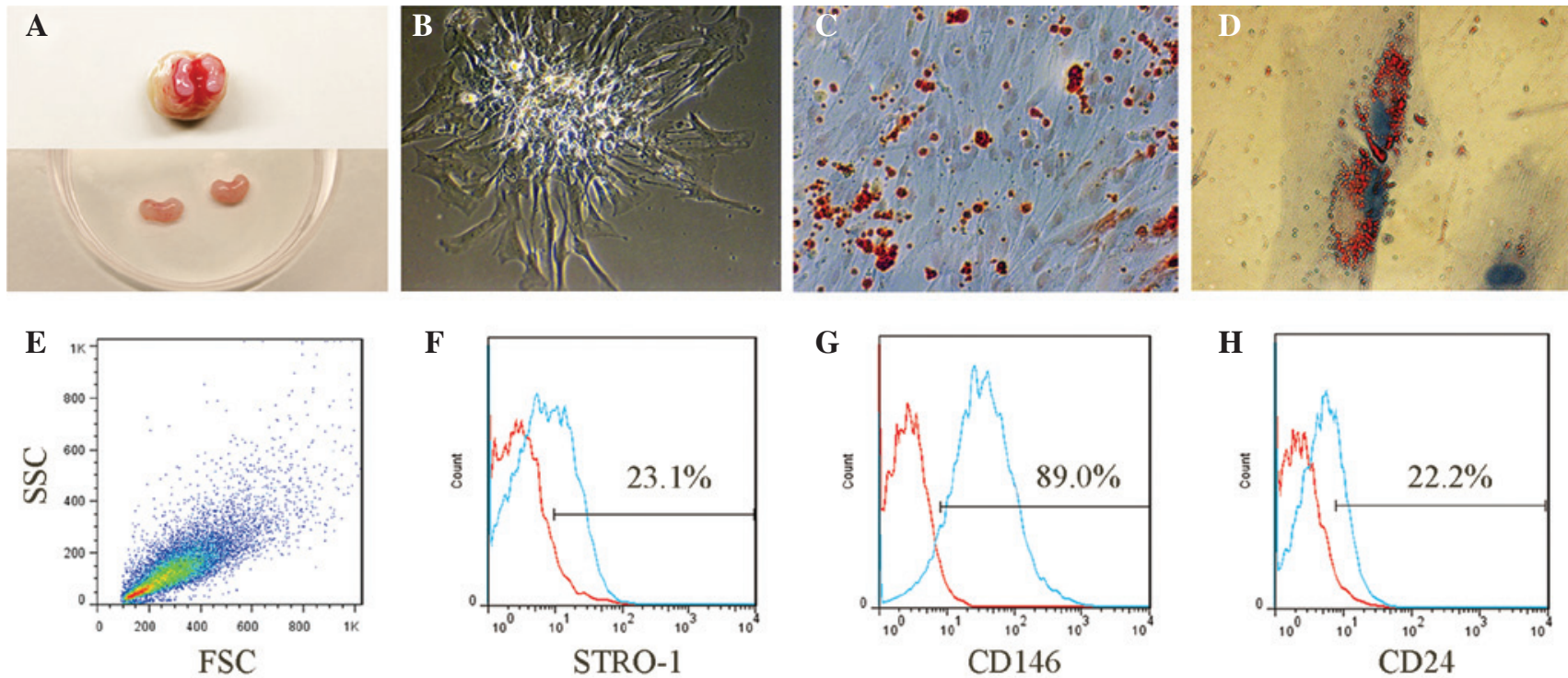

Figure 1. Isolation and identification of SCAP. (A) Apical papillae, which were separated from the apical part of third molars, exhibited with a pink and kidney-shaped appearance. (B) The primary SCAP formed classical cell colonies eight days subsequent to isolation (original magnification, x200). (C) Alizarin red-positive mineralized deposits were observed following 32 days osteogenic induction (original magnification, x100). (D) Oil Red-positive lipid droplets were observed following 16 days adipogenic induction (original magnification, $\mathrm{x} 800$ ). (E) The isolated cells from the apical papilla had the typical FSC/SSC features of SCAP. Representative flow cytometry results demonstrated that the isolated cells had positive expression of (F) STRO-1, (G) CD146 and (H) CD24, which were consistent with the phenotypic characteristics of SCAP. SCAP, stem cells from apical papilla; FSC, forward scatter; SSC, side scatter.

Western blotting. The protein extracts from the four groups of cells were separated on $12 \%$ sodium dodecyl sulfate-polyacrylamide gels (Beyotime Institute of Biotechnology, Haimen, China) and transferred onto polyvinylidene difluoride membranes (Thermo Fisher Scientific, Inc.) at $200 \mathrm{~mA}$ for $2 \mathrm{~h}$. The membranes were blocked with $5 \%$ non-fat milk for $2 \mathrm{~h}$, and were incubated overnight at $4^{\circ} \mathrm{C}$ with the following primary antibodies: Rabbit polyclonal anti-VEGF (1:500; cat. no. ab46154; Abcam, Cambridge, MA, USA); rabbit polyclonal anti-BMP2 (1:500; cat. no. ab14933; Abcam) and rabbit polyclonal anti-dentin sialoprotein (DSP; 1:500; cat. no. sc-33586; Santa Cruz Biotechnology, Inc., Santa Cruz, CA, USA). The membranes were subsequently incubated with a horseradish peroxidase-conjugated goat anti-rabbit antibody (1:20,000; cat. no. ab97051; Abcam) at $37^{\circ} \mathrm{C}$ for $2 \mathrm{~h}$. Rabbit polyclonal anti-GAPDH (1:2,500; cat. no. ab9485; Abcam) was selected as the internal control. The resultant bands were visualized by the Chemiluminescence Western Blotting Detection system (EMD Millipore) on X-ray films (Kodak, Rochester, NY, USA).

ALP staining. The transfected cells were seeded into 6-well plates at an initial density of $5 \times 10^{4}$ cells/well and were cultured to $70 \%$ confluence in $2 \mathrm{ml} \alpha$-MEM containing $15 \% \mathrm{FBS}$. The ALP Staining kit (Jiancheng Biotech. Co., Ltd., Nanjing, China) was used to stain mineralized granules on day 16 subsequent to transfection (11). The number of mineralized nodules was counted three times using an Axio Observer Z1 microscope (Zeiss AG, Oberkochen, Germany) at a magnification of x200.

Statistical analysis. The data are presented as the mean \pm standard deviation, and were evaluated by one-way analysis of variance to analyze the differences between the four groups of cells. SPSS software, version 16.0 (SPSS, Inc., Chicago, IL,
USA) was used for statistical analysis. $\mathrm{P}<0.05$ was considered to indicate a statistically significant difference.

\section{Results}

Morphology, multipotent differentiation and phenotypes of SCAP. The kidney-shaped papillae, which had a dense and pink appearance, were separated from the third molars (Fig. 1A). The isolated primary SCAP presented with a short spindle-like appearance and formed classic cell colonies subsequent to eight days culture (Fig. 1B). Alizarin Red staining illustrated that SCAP formed abundant mineralized nodules 32 days subsequent to osteogenic induction (Fig. 1C), and Oil Red O staining indicated that SCAP formed lipid droplets 16 days following adipogenic induction (Fig. 1D). The freshly isolated SCAP exhibited typical forward scatter/side scatter characteristics (Fig. 1E), similar to those reported previously $(4,7)$. The presence of the phenotypic markers, including STRO-1, CD146 and CD24, were observed to be $23.1 \%, 89.0 \%$ and $22.2 \%$, respectively in the isolated cells (Fig. 1F-H).

Overexpression VEGF and $B M P 2$ in $S C A P$. A total of four days subsequent to transfection, the mRNA expression levels of VEGF in SCAP-GFP, SCAP-BMP2, SCAP-VEGF and SCAP-BMP2-VEGF were $1.00 \pm 0.07,1.32 \pm 0.09$, $11.14 \pm 0.72$ and $9.03 \pm 0.18$, respectively. The relative mRNA expression levels of BMP2 in SCAP-GFP, SCAP-BMP2, SCAP-VEGF and SCAP-BMP2-VEGF were $1.00 \pm 0.12$, $6.79 \pm 0.10,3.11 \pm 0.05$ and $5.94 \pm 0.12$, respectively (Fig. 2A). The relative VEGF protein expression levels, which were quantified by measuring the grayscale of the western blotting bands in SCAP-GFP, SCAP-BMP2, SCAP-VEGF and SCAP-BMP2-VEGF, were $1.00 \pm 0.10,1.09 \pm 0.09$, $2.79 \pm 0.26$ and $3.03 \pm 0.15$, respectively. The relative BMP2 
A

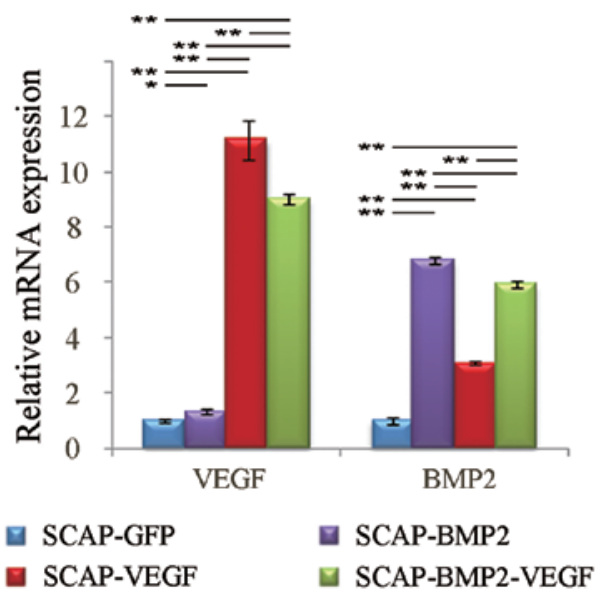

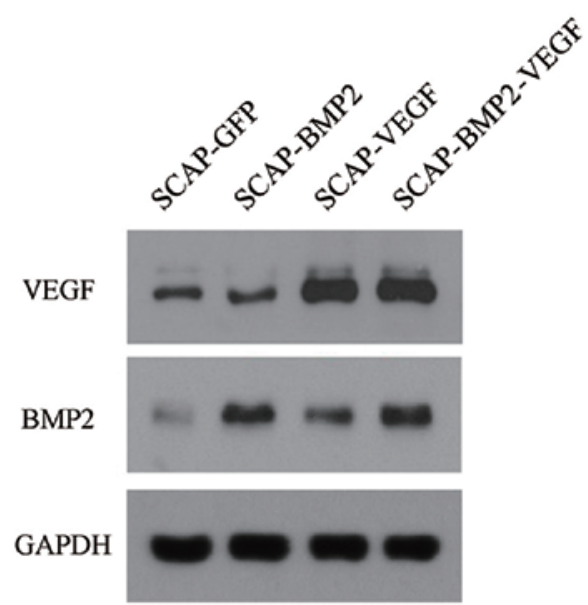

C

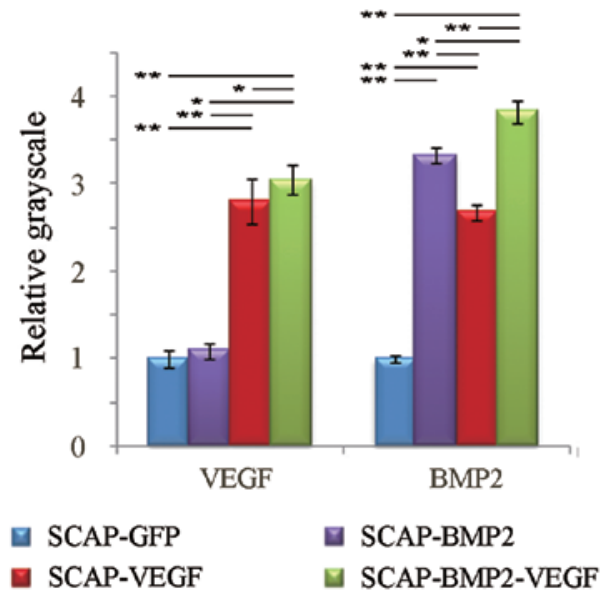

D

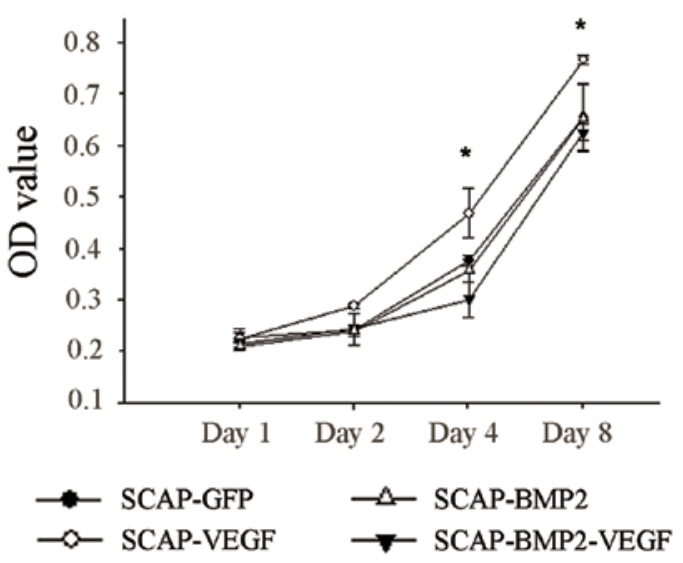

Figure 2. Transfection efficiency and proliferation status. (A) A total of four days subsequent to lentivirus-mediated gene transfection, the relative mRNA expression of VEGF was significantly $(\mathrm{P}<0.05)$ enhanced in SCAP-BMP2, SCAP-VEGF and SCAP-BMP2-VEGF compared with SCAP-GFP. In addition, the relative mRNA expression levels of BMP2 were significantly $(\mathrm{P}<0.05)$ increased in SCAP-BMP2, SCAP-VEGF and SCAP-BMP2-VEGF compared with SCAP-GFP. (B and C) Western blot analysis confirmed that the VEGF peptide expression was significantly $(\mathrm{P}<0.01)$ enhanced in SCAP-VEGF and SCAP-BMP2-VEGF compared with SCAP-GFP, and the BMP2 peptide expression was significantly $(\mathrm{P}<0.01)$ enhanced in SCAP-BMP2, SCAP-VEGF and SCAP-BMP2-VEGF compared with SCAP-GFP. (D) SCAP-VEGF transfection resulted in significantly $(\mathrm{P}<0.05)$ increased OD values, and SCAP-BMP2-VEGF transfection resulted in the lowest $\mathrm{OD}$ values on the 4 th and 8 th days subsequent to gene transfection. ${ }^{*} \mathrm{P}<0.05,{ }^{* * *} \mathrm{P}<0.01$. VEGF, vascular endothelial growth factor; SCAP, stem cells from apical papilla; BMP2, bone morphogenetic protein 2; GFP, green fluorescent protein; OD, optical density; GAPDH, glyceraldehyde 3-phosphate dehydrogenase.

protein expression levels were $1.00 \pm 0.04,3.32 \pm 0.09,2.67 \pm 0.10$ and $3.83 \pm 0.15$, respectively (Fig. $2 \mathrm{~B}$ and $\mathrm{C}$ ). The mRNA and protein expression levels of VEGF and BMP2 were observed to be significantly enhanced in SCAP-BMP2-VEGF compared with SCAP-GFP $(\mathrm{P}<0.05)$ (Fig. 2A-C). Notably, the current results demonstrated that VEGF gene transfection significantly enhanced the BMP2 expression of SCAP $(\mathrm{P}<0.05)$.

VEGF and BMP2 control the proliferation of SCAP. On days 4 and 8 subsequent to lentivirus-mediated gene transfection, SCAP-VEGF exhibited increased proliferation when compared with the other three groups of cells $(\mathrm{P}<0.05)$, while SCAP-BMP2-VEGF exhibited reduced proliferation (Fig. 2D).

$V E G F$ and BMP2 gene co-transfection increased the expression of osteo-/odontogenic gene and protein expression of $S C A P$. The mRNA expression of osteo-/odontogenic genes in SCAP-BMP2-VEGF, including ALP, OCN, DSPP and DMP1, were observed to increase, reaching peak levels of expression on day 16. In addition, the expression of ALP, OCN, DSPP and DMP1 in SCAP-BMP2-VEGF was greater than in the other groups at the majority of the time points measured $(\mathrm{P}<0.05)$ (Fig. 3). Consistent with the mRNA expression results, western blotting indicated that the expression of DSP in SCAP-BMP2-VEGF was significantly increased when compared with the other three groups of cells on days 1,4 , 8 and $16(\mathrm{P}<0.01)$, and the expression increased over time.

Mineralization nodule formation of gene-transfected SCAP. The mineralized nodules, which have a strong positive expression of ALP, were stained with a golden color (Fig. 4). The number of mineralized nodules in the SCAP-BMP2-VEGF group was significantly greater than in the remaining three groups $(\mathrm{P}<0.01)$. In addition, the number of mineralized nodules in the SCAP-BMP2 and SCAP-VEGF groups was observed to be significantly greater than that of SCAP-GFP $(\mathrm{P}<0.01)$. 
A

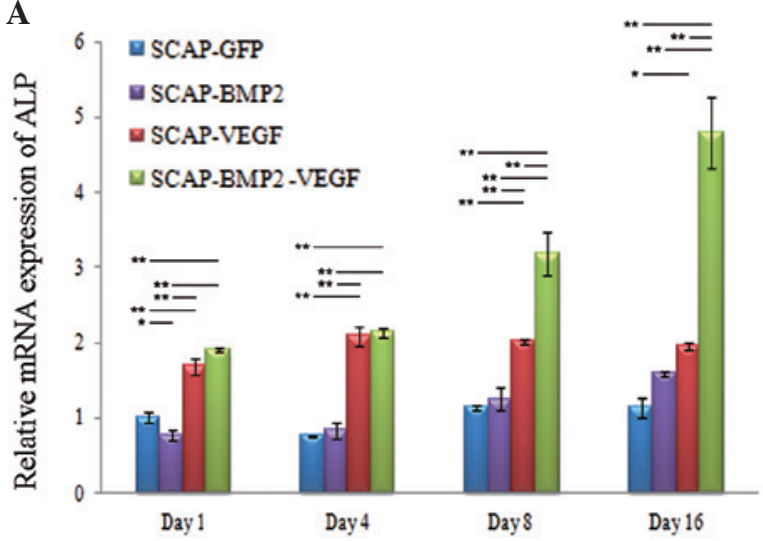

C

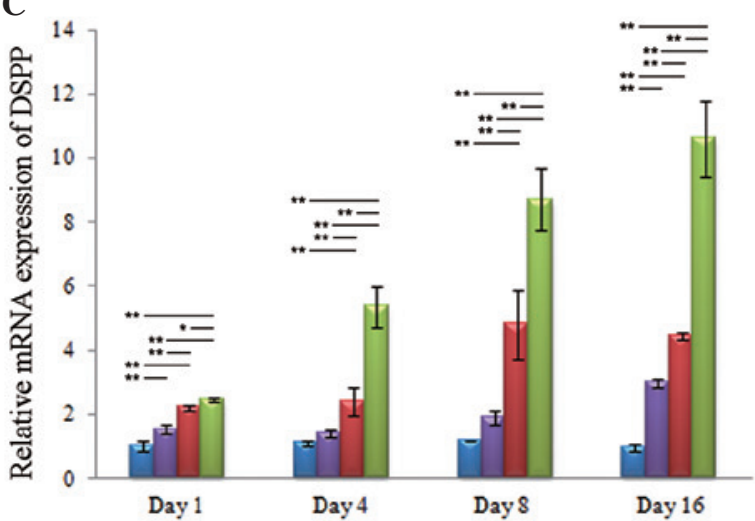

E

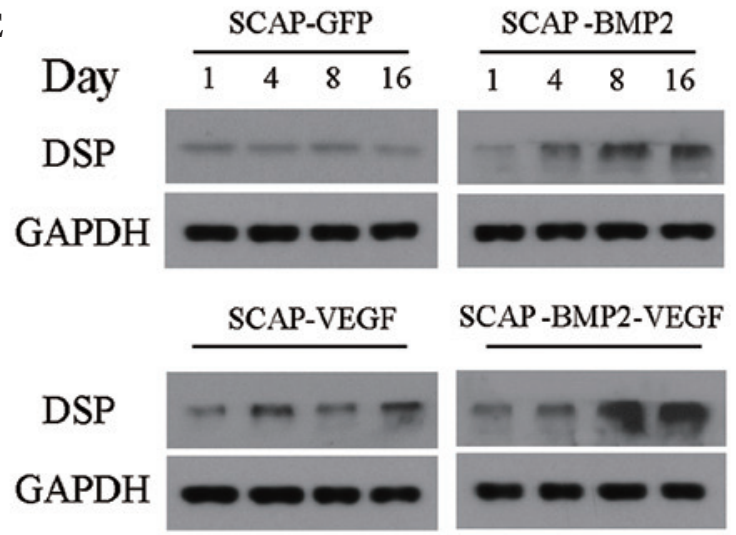

B

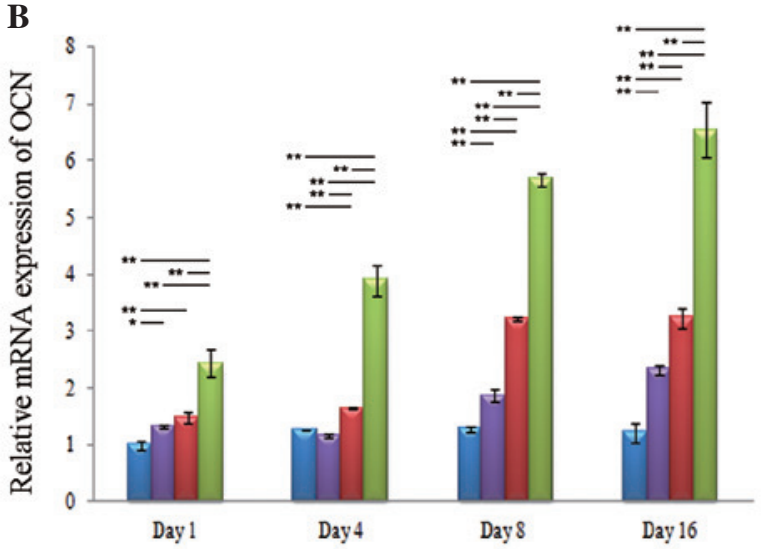

D
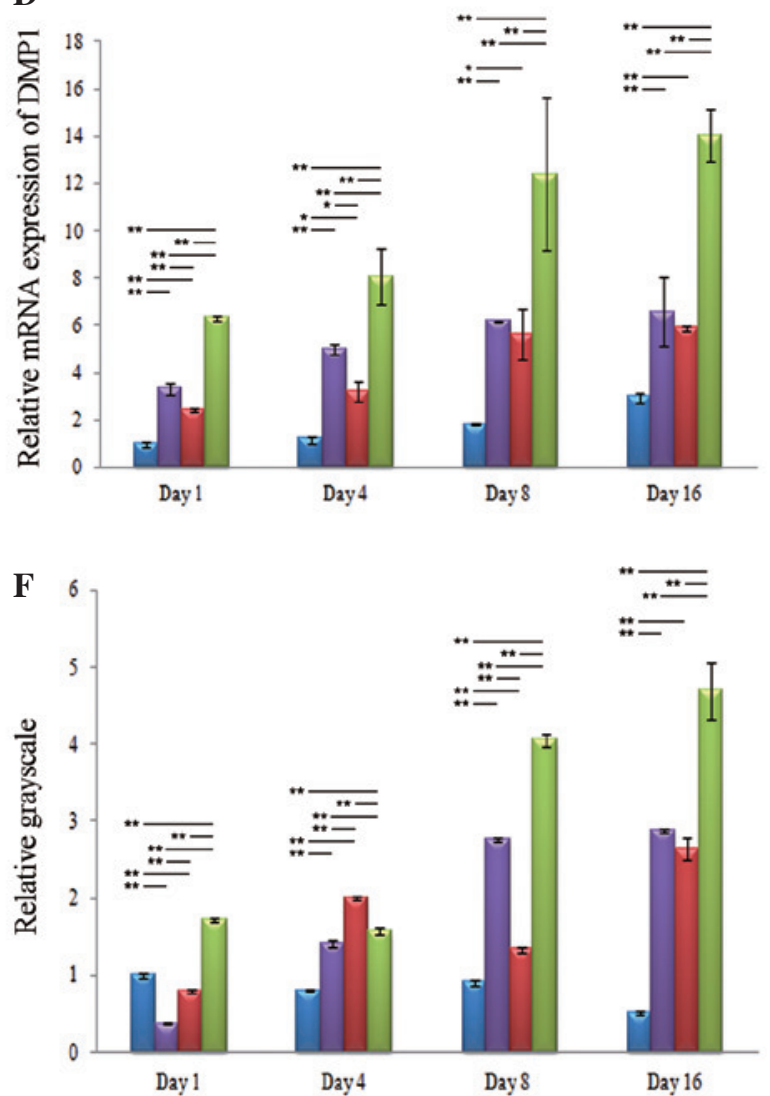

Figure 3. Osteo-/odontogenic differentiation gene mRNA and protein expression levels. The relative mRNA expression levels of (A) ALP, (B) OCN, (C) DSPP and (D) DMP1 in SCAP-BMP2-VEGF was observed to be significantly greater than the other three groups at the majority of the time points (P<0.05), and increases in expression were time-dependent. (E and F) The DSP expression in SCAP-BMP2-VEGF, detected by relative grayscale, was significantly stronger than the other three groups at the majority of the time points $(\mathrm{P}<0.05)$, and increases in expression were broadly time-dependent. $\mathrm{P}<0.05$, ${ }^{* *} \mathrm{P}<0.01$. ALP, alkaline phosphatase; OCN, osteocalcin; DSPP, dentin sialophosphoprotein; DMP1, dentin matrix acidic phosphoprotein gene 1; SCAP, stem cells from apical papilla; BMP2, bone morphogenetic protein 2; VEGF, vascular endothelial growth factor; DSP, dentin sialoprotein; GAPDH, glyceraldehyde 3-phosphate dehydrogenase.

\section{Discussion}

SCAP are multipotent stem cells, which can differentiate into osteoblasts, odontoblasts and adipocytes (1-3). The current study confirmed the osteogenic and adipogenic differentiation capacities of SCAP. In agreement with previous studies $(1-3,7,11,24)$, significant mineralized deposits and lipid droplets were formed by SCAP following osteogenic and adipogenic induction. Furthermore, the isolated cells from apical papilla exhibited the specific phenotypic characteristics of SCAP, including the presence of STRO-1, CD146 and CD24 (3). Previous studies have indicated that the positive percentages in the 1st passage of SCAP were approximately $20-30 \%(3,7), 47-84 \%$ (4) and 3-15\% (7) for STRO-1, CD146 and CD24, respectively. In the present study, the representative expression of STRO-1, CD146 and CD24 of the 2nd passage SCAP was positive, and these results are consistent with previous studies $(3,4,7)$.

Even though SCAP has the capacity to differentiate into osteoblasts and odontoblasts, and can form mineralized tissues 

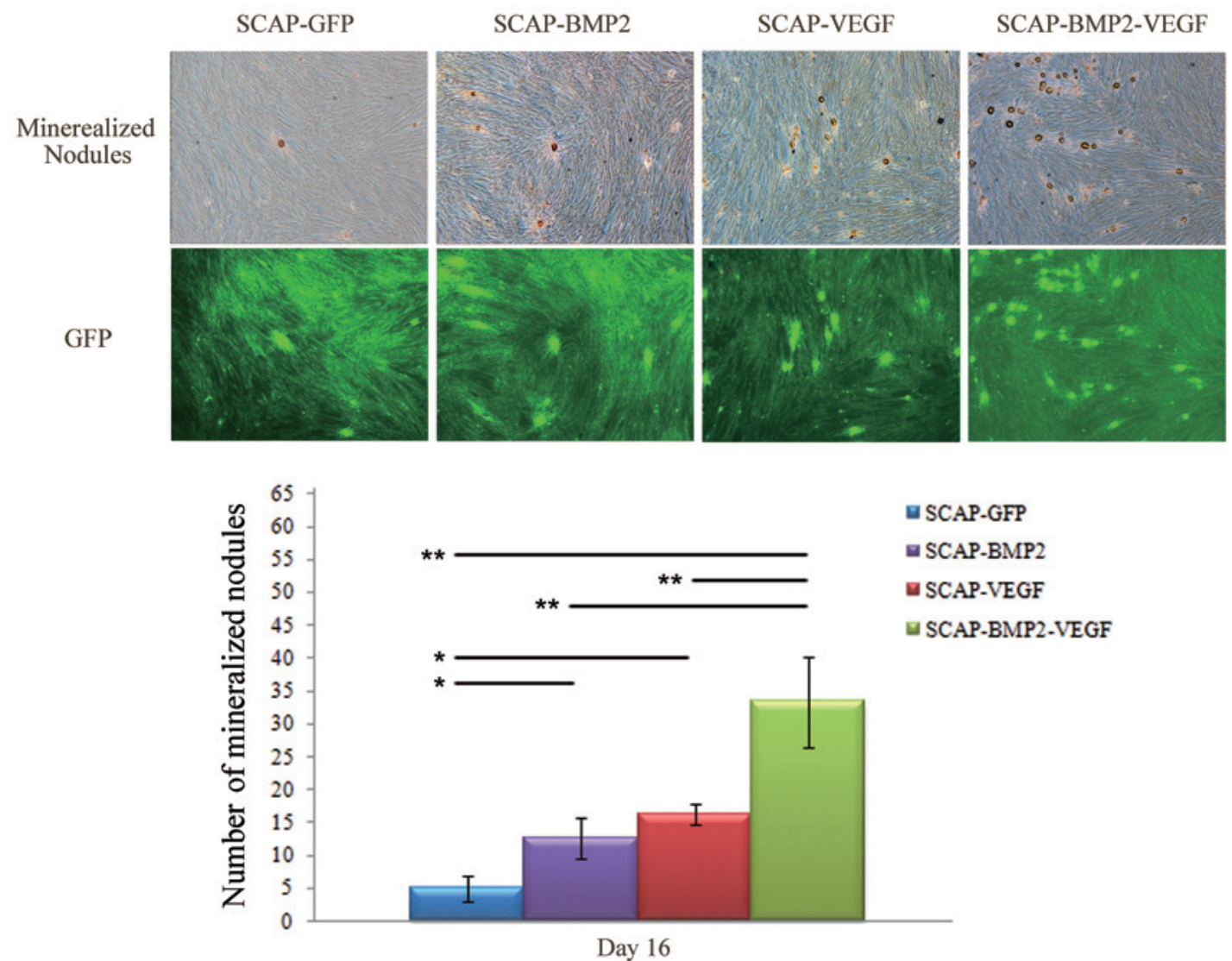

Figure 4. Alkaline phosphatase staining. The mineralized nodules were stained golden/yellow (original magnification, x100). In addition, strong GFP expression was detected in the majority of cells, which indicated that the effectiveness of lentivirus-mediated transfection remained sufficient subsequent to 16 days culture in vitro. The mineralized nodules formed by SCAP-BMP2-VEGF was significantly increased compared with the other groups $(\mathrm{P}<0.01)$. "P<0.05, ${ }^{* *} \mathrm{P}<0.01$. GFP, green fluorescent protein; SCAP, stem cells from apical papilla; BMP2, bone morphogenetic protein 2; VEGF, vascular endothelial growth factor.

in vivo $(9,11,25,26)$, the mechanisms of osteo-/odontogenic differentiation promotion remain to be fully elucidated. VEGF and BMP2, which exhibited specific expression in the proliferation and differentiation of osteoblasts, are regarded as important regulators of osteogenesis $(27,28)$. In a normal bone healing model, VEGF was previously observed to exhibit maximal expression a number of days earlier than for BMP2 (29), indicating the sequence of vascular bed establishment and bone formation. In dentin development, BMP2 and VEGF were detected during the differentiation and maturation process of odontoblasts (30-33). Previous studies have reported that gene transfection of BMP2 or VEGF genes alone was effective in activating the osteo-/odontogenic potential of DPSCs by increasing the expression levels of osteo-/odontogenic genes, including ALP, OCN, COLI, bone sialoprotein, DSP and DMP1 $(12,16)$. ALP, detected in the process of mineralization, was regarded as an early signal of osteo-/odontogenic differentiation of stem cells derived from dental tissues $(24,34,35)$. OCN is typically recognized as a signal of osteo-/odontogenic differentiation at a later stage in the process (4). DMP1 serves an essential role in the maturation of ameloblasts, osteoblasts and odontoblasts, in addition to the progression of mineralization in certain stem cells (36). DSP, the amino-terminal part of DSPP, has been reported to be an important protein during the process of odontogenic differentiation (37). In the current study, the osteo-/odontogenic gene and protein expression levels were observed to be significantly upregulated in SCAP-BMP2 and SCAP-VEGF when compared with SCAP-GFP at the majority of the time points. This indicated that BMP2 or VEGF gene transfection alone aided in enhancing the osteo-/odontogenic differentiation of SCAP.

Previous studies have used combined delivery of BMP2 and VEGF in order to improve osteogenic differentiation of mesenchymal stem cells $(20,22,38-43)$, osteoprogenitor cells $(19,44)$ and osteoblasts $(45)$. When pre-osteoblasts were induced by BMP2, the expression of VEGF was observed to increase (46). Similarly, VEGF gene transfection enhanced the expression of VEGF in the bone marrow stromal cells, in addition to marginally increasing the expression of BMP2 (41). However, a previous study contracted this, stating that VEGF transfection inhibits the expression of BMP2 in mesenchymal stem cells (23). In the current study, VEGF gene transfection was observed to enhance the expression of VEGF, in addition to significantly increasing the expression of BMP2 in SCAP. These results indicated that VEGF may promote the osteo-/odontogenic differentiation of SCAP by acting cooperatively with BMP2. In addition, a previous study demonstrated that VEGF and BMP2 were able to promote bone regeneration by facilitating stem cell homing (39). A previous study indicated that BMP2- and VEGF-co-transfected BMMSCs resulted in the peak ALP expression on day 7 (22). 
However, SCAP-BMP2-VEGF demonstrated an increased expression of ALP over time in the current study. The results of current study supported the hypothesis that BMP2 and VEGF gene co-transfection was more effective in improving osteo-/odontogenic differentiation of SCAP than single gene transfection.

A previous study indicated that VEGF increased the rate of proliferation in rat osteoblasts in a dose-dependent manner, while no significant alterations were observed with BMP2 (45). The results of the present study are consistent with this previous study (45), observing that the VEGF-transfected SCAP group exhibited marginally increased proliferation compared with the other groups on days 4 and 8 subsequent to transfection. The lowest levels of proliferation were observed in the BMP2 and VEGF co-transfection group on days 4 and 8, thus the BMP2 and VEGF had a synergistic effect on the proliferation of SCAP.

In summary, human dental papilla stem cells were successfully transfected with the BMP2 and VEGF genes. The SCAP-BMP2-VEGF group exhibited increased expression levels of osteo-/odontogenic differentiation-associated genes and protein, and increased mineralization deposits than the SCAP-BMP2, SCAP-VEGF and SCAP-GFP groups in vitro. These results suggest that the co-transfection of homologous BMP2 and VEGF genes is an effective strategy to improve the osteo-/odontogenic differentiation of SCAP in vitro.

\section{References}

1. Huang GT, Sonoyama W, Liu Y, Liu H, Wang S and Shi S: The hidden treasure in apical papilla: The potential role in pulp/dentin regeneration and bioroot engineering. J Endod 34: 645-651, 2008.

2. Sonoyama W, Liu Y, Fang D, Yamaza T, Seo BM, Zhang C, Liu H, Gronthos S, Wang CY, Wang S and Shi S: Mesenchymal stem cell-mediated functional tooth regeneration in swine. PloS One 1: e79, 2006.

3. Huang GT, Gronthos S and Shi S: Mesenchymal stem cells derived from dental tissues vs. those from other sources: Their biology and role in regenerative medicine. J Dent Res 88: 792-806, 2009.

4. Bakopoulou A, Leyhausen G, Volk J, Tsiftsoglou A, Garefis P, Koidis P and Geurtsen W: Comparative analysis of in vitro osteo/odontogenic differentiation potential of human dental pulp stem cells (DPSCs) and stem cells from the apical papilla (SCAP). Arch Oral Biol 56: 709-721, 2011.

5. Tziafas D and Kodonas K: Differentiation potential of dental papilla, dental pulp and apical papilla progenitor cells. J Endod 36: 781-789, 2010.

6. Lin CS, Xin ZC, Dai J and Lue TF: Commonly used mesenchymal stem cell markers and tracking labels: Limitations and challenges. Histol Histopathol 28: 1109-1116, 2013.

7. Bakopoulou A, Leyhausen G, Volk J, Koidis P and Geurtsen W: Comparative characterization of STRO-1 (neg)/CD146 (pos) and STRO-1 (pos)/CD146 (pos) apical papilla stem cells enriched with flow cytometry. Arch Oral Biol 58: 1556-1568, 2013.

8. Friedlander LT, Cullinan MP and Love RM: Dental stem cells and their potential role in apexogenesis and apexification. Int Endod J 42: 955-962, 2009.

9. Wang J, Zhang H, Zhang W, Huang E, Wang N, Wu N, Wen S, Chen X, Liao Z, Deng F, et al: Bone morphogenetic protein-9 effectively induces osteo/odontoblastic differentiation of the reversibly immortalized stem cells of dental apical papilla. Stem Cells Dev 23: 1405-1416, 2014.

10. Lin ZM, Qin W, Zhang NH, Xiao L and Ling JQ: Adenovirus-mediated recombinant human bone morphogenetic protein-7 expression promotes differentiation of human dental pulp cells. J Endod 33: 930-935, 2007.

11. Zhang W, Zhang X, Ling J, Liu W, Ma J and Zheng J: Proliferation and odontogenic differentiation of BMP2 genetransfected stem cells from human tooth apical papilla: An in vitro study. Int J Mol Med 34: 1004-1012, 2014.
12. Yang X, van der Kraan PM, Bian Z, Fan M, Walboomers XF and Jansen JA: Mineralized tissue formation by BMP2-transfected pulp stem cells. J Dent Res 88: 1020-1025, 2009.

13. Hiltunen MO, Ruuskanen M, Huuskonen J, Mähönen AJ, Ahonen M, Rutanen J, Kosma VM, Mahonen A, Kröger H and Ylä-Herttuala S: Adenovirus-mediated VEGF-A gene transfer induces bone formation in vivo. FASEB J 17: 1147-1149, 2003.

14. Jacobsen KA, Al-Aql ZS, Wan C, Fitch JL, Stapleton SN, Mason ZD, Cole RM, Gilbert SR, Clemens TL, Morgan EF, et al: Bone formation during distraction osteogenesis is dependent on both VEGFR1 and VEGFR2 signaling. J Bone Miner Res 23: 596-609, 2008

15. Dvorak HF: Angiogenesis: Update 2005. J Thromb Haemost 3: $1835-1842,2005$

16. Zhang W, Liu W, Ling J, Lin Z, Gao Y, Mao X and Jian Y: Odontogenic differentiation of vascular endothelial growth factor-transfected human dental pulp stem cells in vitro. Mol Med Rep 10: 1899-1906, 2014.

17. Lee JH, Um S, Jang JH and Seo BM: Effects of VEGF and FGF-2 on proliferation and differentiation of human periodontal ligament stem cells. Cell Tissue Res 348: 475-484, 2012.

18. Matsushita K, Motani R, Sakuta T, Yamaguchi N, Koga T, Matsuo K, Nagaoka S, Abeyama K, Maruyama I and Torii M: The role of vascular endothelial growth factor in human dental pulp cells: Induction of chemotaxis, proliferation and differentiation and activation of the AP-1-dependent signaling pathway. $\mathrm{J}$ Dent Res 79: 1596-1603, 2000.

19. Kanczler JM, Ginty PJ, White L, Clarke NM, Howdle SM, Shakesheff KM and Oreffo RO: The effect of the delivery of vascular endothelial growth factor and bone morphogenic protein-2 to osteoprogenitor cell populations on bone formation. Biomaterials 31: 1242-1250, 2010.

20. Kumar S, Wan C, Ramaswamy G, Clemens TL and Ponnazhagan S: Mesenchymal stem cells expressing osteogenic and angiogenic factors synergistically enhance bone formation in a mouse model of segmental bone defect. Mol Ther 18: 1026-1034, 2010.

21. Lin CY, Chang YH, Lin KJ, Yen TC, Tai CL, Chen CY, Lo WH, Hsiao IT and Hu YC: The healing of critical-sized femoral segmental bone defects in rabbits using baculovirus-engineered mesenchymal stem cells. Biomaterials 31: 3222-3230, 2010.

22. Lin Z, Wang JS, Lin L, Zhang J, Liu Y, Shuai M and Li Q: Effects of BMP2 and VEGF165 on the osteogenic differentiation of rat bone marrow-derived mesenchymal stem cells. Exp Ther Med 7: 625-629, 2014

23. Schönmeyr BH, Soares M, Avraham T, Clavin NW, Gewalli F and Mehrara BJ: Vascular endothelial growth factor inhibits bone morphogenetic protein 2 expression in rat mesenchymal stem cells. Tissue Eng Part A 16: 653-662. 2010.

24. Chen K, Xiong H, Huang Y and Liu C: Comparative analysis of in vitro periodontal characteristics of stem cells from apical papilla (SCAP) and periodontal ligament stem cells (PDLSCs). Arch Oral Biol 58: 997-1006, 2013.

25. Wang J, Liu B, Gu S and Liang J: Effects of Wnt/ $\beta$-catenin signalling on proliferation and differentiation of apical papilla stem cells. Cell Prolif 45: 121-131, 2012.

26. Qu B, Liu O, Fang X, Zhang H, Wang Y, Quan H, Zhang J, Zhou J, Zuo J, Tang J and Tang Z: Distal-less homeobox 2 promotes the osteogenic differentiation potential of stem cells from apical papilla. Cell Tissue Res 357: 133-143, 2014.

27. Dai J and Rabie AB: VEGF: An essential mediator of both angiogenesis and endochondral ossification. J Dent Res 86: 937-950, 2007.

28. Ryoo HM, Lee MH and Kim YJ: Critical molecular switches involved in BMP-2-induced osteogenic differentiation of mesenchymal cells. Gene 366: 51-57, 2006.

29. Uchida S, Sakai A, Kudo H, Otomo H, Watanuki M, Tanaka M, Nagashima $\mathrm{M}$ and Nakamura T: Vascular endothelial growth factor is expressed along with its receptors during the healing process of bone and bone marrow after drill-hole injury in rats. Bone 32: 491-501, 2003

30. Casagrande L, Demarco FF, Zhang Z, Araujo FB, Shi S and Nör JE: Dentin-derived BMP-2 and odontoblast differentiation. J Dent Res 89: 603-608, 2010.

31. Mastrangelo F, Piccirilli M, Dolci M, Teté S, Speranza L, Patruno A, Gizzi F, Felaco M, Artese L and De Lutiis MA: Vascular endothelial growth factor (VEGF) in human tooth germ center. Int J Immunopathol Pharmacol 18: 587-594, 2005 . 
32. Scheven BA, Man J, Millard JL, Cooper PR, Lea SC, Walmsley AD and Smith AJ: VEGF and odontoblast-like cells: Stimulation by low frequency ultrasound. Arch Oral Biol 54: 185-191, 2009.

33. Virtej A, Løes S, Iden O, Bletsa A and Berggreen E: Vascular endothelial growth factors signalling in normal human dental pulp: A study of gene and protein expression. Eur J Oral Sci 121 : 92-100, 2013

34. Wu J, Huang GT, He W, Wang P, Tong Z, Jia Q, Dong L, Niu Z and Ni L: Basic fibroblast growth factor enhances stemness of human stem cells from the apical papilla. J Endod 38: 614-622, 2012.

35. Choi MH, Noh WC, Park JW, Lee JM and Suh JY: Gene expression pattern during osteogenic differentiation of human periodontal ligament cells in vitro. J Periodontal Implant Sci 41: 167-175, 2011.

36. MacDougall M, Gu TT and Simmons D: Dentin matrix protein-1, a candidate gene for dentinogenesis imperfecta. Connect Tissue Res 35: 267-272, 1996.

37. Lee SY, Kim SY, Park SH, Kim JJ, Jang JH and Kim EC: Effects of recombinant dentin sialoprotein in dental pulp cells. J Dent Res 91: 407-412, 2012.

38. Zhang W, Zhu C, Ye D, Xu L, Zhang X, Wu Q, Zhang X, Kaplan DL and Jiang X: Porous silk scaffolds for delivery of growth factors and stem cells to enhance bone regeneration. PloS One 9: e102371, 2014

39. Zhang W, Zhu C, Wu Y, Ye D, Wang S, Zou D, Zhang X, Kaplan DL and Jiang X: VEGF and BMP-2 promote bone regeneration by facilitating bone marrow stem cell homing and differentiation. Eur Cell Mater 27: 1-11; discussion 11-12, 2014.
40. Bai Y, Li P, Yin G, Huang Z, Liao X, Chen X and Yao Y: BMP-2, VEGF and bFGF synergistically promote the osteogenic differentiation of rat bone marrow-derived mesenchymal stem cells. Biotechnol Lett 35: 301-308, 2013.

41. Xiao C, Zhou H, Liu G, Zhang P, Fu Y, Gu P, Hou H, Tang T and Fan X: Bone marrow stromal cells with a combined expression of BMP-2 and VEGF-165 enhanced bone regeneration. Biomed Mater 6: 015013, 2011.

42. Tian XB, Sun L, Yang SH, Fu RY, Wang L, Lu TS, Zhang YK and Fu DH: Ectopic osteogenesis of mouse bone marrow stromal cells transfected with BMP 2/VEGF (165) genes in vivo. Orthop Surg 1: 322-325, 2009.

43. Hou H, Zhang X, Tang T, Dai K and Ge R: Enhancement of bone formation by genetically-engineered bone marrow stromal cells expressing BMP-2, VEGF and angiopoietin-1. Biotechnol Lett 31: 1183-1189, 2009.

44. Behr B, Sorkin M, Lehnhardt M, Renda A, Longaker MT and Quarto N: A comparative analysis of the osteogenic effects of BMP-2, FGF-2 and VEGFA in a calvarial defect model. Tissue Eng Part A 18: 1079-1086, 2012.

45. Li P, Bai Y, Yin G, Pu X, Huang Z, Liao X, Chen X and Yao Y: Synergistic and sequential effects of BMP-2, bFGF and VEGF on osteogenic differentiation of rat osteoblasts. J Bone Miner Metab 32: 627-635, 2014

46. Akeel S, El-Awady A, Hussein K, El-Refaey M, Elsalanty M, Sharawy M and Al-Shabrawey M: Recombinant bone morphogenetic protein-2 induces up-regulation of vascular endothelial growth factor and interleukin 6 in human pre-osteoblasts: Role of reactive oxygen species. Arch Oral Biol 57: 445-452, 2012. 